Blockchains and Cryptocurrencies
International Journal of Blockchains and Cryptocurrencies

ISSN online: 2516-6433 - ISSN print: 2516-6425

https://www.inderscience.com/ijbc

\title{
Decentralised application for crowdfunding using blockchain technology
}

H.L. Gururaj, V. Janhavi, Abhishek M. Holla, Ashwin A. Kumar, R. Bhumika and Sam Goundar

DOI: $\underline{10.1504 / / J B C .2021 .117809}$

\section{Article History:}

Received:

Last revised:

Accepted:

Published online:
19 May 2020

19 May 2020

27 January 2021

07 September 2021 


\title{
Decentralised application for crowdfunding using blockchain technology
}

\section{H.L. Gururaj*, V. Janhavi, Abhishek M. Holla, Ashwin A. Kumar and R. Bhumika}

Vidyavardhaka College of Engineering,

Mysuru, 570002, India

Email: gururaj1711@vvce.ac.in

Email: janhavi.v@vvce.ac.in

Email: abhishek.holla98@gmail.com

Email: ashwinkumar.cs@vvce.ac.in

Email: bhumika.r1206@gmail.com

*Corresponding author

\section{Sam Goundar}

British University Vietnam,

Level 5, CDC building, 25-27 Le Dai Hanh,

Hai Ba Trung, Hanoi, Vietnam

and

Staffordshire University,

University Quarter,

College Road, Stoke-on-Trent,

Staffordshire ST4 2DE, UK

Email: sam.goundar@gmail.com

\begin{abstract}
Crowdfunding is a way for people, businesses, and charities to raise money. It works through individuals or organisations who invest in (or donate to) crowdfunding projects in return for a potential profit or reward. Investing this way can be risky. Security is the main challenging issue in crowdfunding contracts. Using existing literature on crowdfunding and blockchain technology, they put forward a conceptual framework that can provide the solution to the problems related to crowdfunding contracts using blockchain technology. This methodology points out the potential of crowdfunding decentralised applications to lower market inefficiencies by bypassing third parties and easing trades on secondary markets. This platform eliminates the interference of the middlemen. It is highly transparent and secure. A decentralised approach to crowdfunding forfeits all fees for the investor. It also gives a share of the project to the receiver. This model establishes a flexible platform for the fundraiser to start a campaign. The funders invest the amount if they feel the project to be genuine. Once $50 \%$ of the funds are received, it will be transferred to the initiator. It establishes a peer-to-peer relationship between the investor and the receiver.
\end{abstract}

Keywords: crowdfunding; blockchain; smart contracts; peer-to-peer network; internet. 
Reference to this paper should be made as follows: Gururaj, H.L., Janhavi, V., Holla, A.M., Kumar, A.A., Bhumika, R. and Goundar, S. (2021) 'Decentralised application for crowdfunding using blockchain technology', Int. J. Blockchains and Cryptocurrencies, Vol. 2, No. 1, pp.68-82.

Biographical notes: H.L. Gururaj is working as an Assistant Professor in the Department of Computer Science and Engineering at Vidyavardhaka College of Engineering, Mysuru, India. He received the Young Scientist Award for International Travel Grants from ITS-SERB, DST, Government of India. He is an ACM professional member and a faculty sponsor of VVCE ACM Student Chapter. His main research interests include QoS aware network congestion control, network security, cloud computing and machine learning.

V. Janhavi completed her BE in Computer Science and Engineering from VTU, Belagavi, Karnataka, India and MS in Computer Networks, Devry USA and $\mathrm{PhD}$ from VTU Belagavi, Karnataka. She is currently serving as an Associate Professor in the Department of Computer Science and Engineering at Vidyavardhaka College of Engineering, Mysuru, India. Her main research interests include data science, cloud computing, internet of things and artificial intelligence.

Abhishek M. Holla completed his Bachelor of Engineering in Computer Science at Vidyavardhaka College of Engineering, Mysuru, India. He is the Chair of VVCE ACM Chapter and his research interests include blockchain technology, machine learning and IoT.

Ashwin A. Kumar completed his Bachelor of Engineering in Computer Science at Vidyavardhaka College of Engineering, Mysuru, India. He is the Treasurer of VVCE ACM Chapter and his main research interest includes cyber security and blockchain technology.

R. Bhumika completed her Bachelor of Engineering in Computer Science and Engineering at Vidyavardhaka College of Engineering, Mysuru, India. Her main research interests include blockchain technology, decentralised storage and machine learning.

Sam Goundar is an Editor-in-Chief of the International Journal of Block Chains and Cryptocurrencies (IJFC) - Inderscience Publishers, Editor-in-Chief of the International Journal of Fog Computing (IJFC) - IGI Publishers, Section Editor of the Journal of Education and Information Technologies (EAIT) - Springer and Editor-in-Chief (Emeritus) of the International Journal of Cloud Applications and Computing (IJCAC) - IGI Publishers. As an academic, he has been teaching information systems (IS), information technology (IT), management information systems (MIS) and computer science (CS) over the last 25 years at several universities in a number of countries at all levels.

\section{Introduction}

In the modern world, the most popular way of financing projects is crowdfunding. An individual or an organisation can pitch the idea for their project. Besides, that people who find this idea genuine will invest (Tomczak and Brem, 2013). The internet has however made crowdfunding more accessible. In 2003, the first-ever crowdfunding site named 
'Artistshare' was launched. Since then, many crowdfunding sites have started namely Kickstarter, RocketHub, Gofundme and Indiegogo. Crowdfunding is one of the hot industries, these days (Chen, 2018).

There are different types of crowdfunding such as reward-based, donation-based, equity-based and lending-based crowdfunding. Reward-based is a scheme where the investors are offered any kind of product or service in return for money. Donation-based: this scheme is more of a charity where investors do not get back anything returns for their donations. Equity-based: in this scheme, the investors become shareholders and are entitled to a share of the profits in a company. Lending-based: in this scheme, the investors lend the money to an organisation, and this organisation is abided by certain restrictions such as the time limit for the return of money to the investors (Greenspan, 2015).

Many crowdfunding platforms operate on an all-or-nothing funding model. This means that if the target is reached the money is received otherwise it is sent back to the investors. Hence, there is no financial loss. Financial pledges are made and collected through the crowdfunding platform. If the fundraising campaign is successful, the fundraisers are charged a small amount of fee. In turn, the crowdfunding platforms need to provide a secure and transparent service for the fundraisers (Knezevic, 2013).

Crowdfunding is one of the most popular methods of raising money for various projects.

Crowdfunding allows investors to choose from hundreds of projects available and invest as little as $\$ 10$. The idea of crowdfunding is a strong alternative where the banks are either unable to or unwilling to lend money. Crowdfunding allows people to fund their projects when the alternative method is not feasible. Crowdfunding is expeditiously expanding. Fortunately, governments all over the world have consented to crowdfund. It sees this as an opportunity to increase the economy of the country by creating more jobs for the people (Tarun, 2015; Schwartz, 2013).

There is a significant difference between crowdfunding and traditional fundraising. In crowdfunding, there is a need to attract a large group of people who donate or invest money eventually reaching the target capital required. However, in traditional finance, only one or two large business firms or organisations who invest the entire amount are needed. It can also include a loan from a bank or other financing institutions. It is fundamentally the opposite of the mainstream approach of traditional business (Ordanini et al., 2011).

The absence of a formal banking system in crowdfunding makes the procedure less tedious. The application process for crowdfunding is highly simplified. It is efficient and thus consumes less time. It intensifies the productivity of innovation and entrepreneurship. It assists in the elevation and progress of small and medium-scale industries by improving the ease of doing business policy. It has various applications such as blogging, journalism, music, independent film, funding start-ups, etc. (Schwartz, 2013). It is an efficient way to give back to society. It allows creators to attain low-cost capital. The results of crowdfunding include larger publicity, a stronger customer base, and an easier time finding employees (Gururaj et al., 2020).

High momentum created by the crowdfunding campaign results in the higher attraction of potential investors including traditional channels and media outlets. Crowdfunding allows people to donate or invest in the field of food and agriculture. AgFunder is one of such a global platform. It bypasses caste or gender prejudice to community network and hence inclusiveness is enhanced. It helps is reducing cost as the 
crowdfunding platform reduces search and transaction costs which in turn allows higher participation in the market. This acts as an opportunity to open up some neglected markets to individuals (Chiu and Koeppl, 2017).

Crowdfunding increases the value of the company as the investors add value to it. Crowdfunding, though considered as an advancement in technology it does have some concerns. It could be of high risk for the new small-scale investors and entrepreneurs and hence they often tend to not achieve their goals in their novice ventures. Reputation is mangled if the goals and targets are not achieved. Failing to generate interest can result in public failure (Schwartz, 2013).

Intellectual property protection can be an issue. Creators engaging in crowdfunding platforms are required to release their product to the public in the early stages of funding. This exposes them to the risk of copy by competitors. Sometimes, if the same network of investors and supporters are reached out repeatedly, in due of course, that network will eventually cease to supply the necessary support. There is a fear of public misuse because of the absence of a regulatory framework. Chances of fraud and money laundering are high here as there does not exist any formal banking system (Sahdev, 2017). Creditworthiness and enforceability are the major stumbling block. There is a lack of expertise as the ratio of the novice is high. The chances of failure are very high due to the immaturity in the start-up sector in India.

There is a way forward. Complete transparency and accountability could do away with fraud and illegal activities by spreading awareness with the help of social media. A seal is to be set to make sure that all the money reaches the destination without the interference of any middle party. To ensure that the funds collected are not misused at any cost, the necessity of documentation increases. To ensure this, blockchain technology can be used which is an immutable ledger to store digital transactions (Ordanini et al., 2011). It helps in eliminating a single point of failure (Athreya et al., 2019). The government can support by issuing laws to support the crowdfunding and entrepreneurship in the country. A pro-business environment is necessary for crowdfunding to be successful.

The paper is structured as follows: Section 2 depicts the related work, Section 3 gives the existing methods, in Section 4, decentralised blockchain application for crowdfunding and algorithm is depicted followed by Section 5 with result analysis, and in Section 6 draws the conclusions and future enhancement.

\section{Related work}

Numerous studies have been done related to crowdfunding and decentralised applications. In this section, the recent research on crowdfunding is elaborated.

Benila et al. (Ordanini et al., 2011) worked towards providing interactive forms for campaign creation, donation, and request approval through which both campaign creators and donors can easily create and fund the campaigns. The donor will be able to track the money they received and the blockchain will record all the transactions and store as a block. This ensures transparency in the transaction process. Any third party interference is highly possible in this kind of system. The creators need to create interactive forms and come up with ideas that could attract a huge public crowd so that the campaigns can be successful. 
Muneeza et al. (Gleasure and Morgan, 2017) contributed to the surfacing literature on financial technology. This was done by presenting the case of crowdfunding in financial inclusion. The logic behind this exploration is to demonstrate the applicability of financial inclusion and how blockchain will be fuelling the progress of crowdfunding. This is one of the first attempts to analyse crowdfunding in Malaysia. Several journals, newspapers, industry reports published on the subject matter were critically reviewed. Six prominent crowdfunding platforms were examined to analyse the development of crowdfunding in Malaysia. The result of this research implies that crowdfunding is a feasible means to promote financial inclusion and thus, blockchain would eventually reduce the issues faced by the platform operators.

Bhogan et al. (Knezevic, 2013) proposed a solution to make the e-tendering process secure by making sure that the tendering organisation cannot change the tender as it is based on the blockchain and cannot read the bid until a deadline is expired. This solution also does not let bidders see or change the bids of other organisations. E-tendering is widely being adopted in modern days. It is more efficient than the traditional paper-based tender processes. The most important security requirements are those that are dependent on legal requirements. In their model, the TTP serves as a bank or a financial institution. It is also responsible for authenticating the tenders and principal.

Rawat et al. (Chiu and Koeppl, 2017) presented a systematic and comprehensive overview of smart contracts enabled by blockchain to stimulate further research in this area. A smart contract is nothing but a digital contract with some security coding. It contains permissions written in code which requires particular events to occur which in turn triggers the agreement of the terms stated in the smart contract. The model contains certain time constraints that will be able to introduce deadlines in the contract. The model uses blockchain and thus making it more transparent, immutable, decentralised and inexpensive.

Shaji et al. (Collins, 2016) proposed a system that will act as a bridge between the landlords and farmers. This system will help farmers to easily lend lands from landlords. Due to the lack of knowledge in agriculture and farming, certain factors need to be checked while lending land such as availability. Though the land lending process is carried out the interaction between farmer and landlord, in most cases, there will be third party interference for enquiring the land details. The model thus proposed makes sure the entire process is carried out by the farmers and the landlords themselves without any outside interference.

Suganya et al. (Greenspan, 2015) developed a system that allowed the users to create their wallets. The wallets are also provided with public and private keys using elliptic-curve cryptography. The transfer of funds is secured by using a digital signature algorithm. There exist two concerns with ECDSA that is political concerns and technical concerns. The trustworthiness of NIST-produced curves was being questioned. This happened after the NSA willingly inserts backdoors into software and hardware components. There is also difficulty in implementing the standards. It is extremely slow and contains design flaws that reduce security in inadequately defensive implementations.

Rakkini et al. (Tarun, 2015) developed an Android app with blockchain architecture which is a holistic approach to transfer money within a small group of peers. Peer to peer money transfer using an Android app built using blockchain architecture is a highly comprehensive approach. Using this app, individuals can transfer money within a small group of peers who lend, borrow, and transfer using e-wallets. Money transfer using this 
system will be unavoidable soon. It calls for security, transparency, and is tamper-proof. All the transactions are recorded in a distributed ledger stored in real-time cloud database firebase with homomorphic encryption.

Knezevic et al. (Tomczak and Brem, 2013) researched the impact of blockchain technology on the financial sector through cryptocurrency. The research was not limited to this technology but also its commercial exploitation. The research started with the analysis of functions of the technology and moved on to understanding its advantages for business and economic transactions and finally dealt with the impact of this new technology on business. The basic hypothesis was such that blockchain has indeed a great impact on the financial sector. It also has the potential power to radically change the way we buy and sell.

Yoo et al. (Sahdev, 2017) proposed a paper that examined the applications of blockchain on the financial sector and how to respond and approach the Korean conditions. They first examined domestic and foreign cases. It was observed that the areas where blockchain is applied especially in the financial sector are expanding into the settlement, securities, smart contracts and remittance. Berns et al. (Schwartz, 2013) used a social responsibility lens to examine whether crowd-funders lend their money based on altruistic or strategic motives. They used the social responsibility lens to analyse the crowd-funders lend money based on altruistic motives or strategic motives. Their results indicated that the lending-based crowdfunding was to a certain level consistent with traditional forms for financing. Crowdfunders tend to act strategically and respond positively to signals of quality and low risk despite the altruistic setting in nature. Additionally, it was observed that the projects that receive the highest average amount of funding are usually both financial and social appealing.

Gleasure and Morgan (2017) explored the social resources that enabled self-hosted crowdfunding activities. Crowdfunding technologies want to replace third party crowdfunding websites. This is done by embedding the required technology directly into fund seekers' websites. This ensures more control and power for fund seekers. Consequently, there arises a major task for this type of fund seekers. They must be capable of gathering a large crowd. The study was performed under certain theoretical lenses namely activity theory and social capital theory. An extreme case of self-hosted crowdfunding was analysed bases on these lenses.

Schär et al. (2019) presented an approach to ease access to capital for start-ups. In this approach, the tokenisation of equity crowdfunding on blockchain was presented. They proposed a categorisation of token standards into certain tokens such as UTXO-based, smart contract-based and layer-based. In the later steps, they performed analyses on the advantages that tokenisation could bring. These advantages included the programmability of assets, cryptographically secured ownership, etc. They came up with a conclusion pointing out several drawbacks including regulatory issues and asymmetries which exist between investors and campaign creators.

Ordanini et al. (2011) analysed the emerging crowd-funding phenomenon, an effort by the consumers to invest in organisations. This research addressed two main research questions: on what grounds do consumers turn into crowdfunding participants? And what makes the service providers setup a crowdfunding initiative? This paper addresses an emerging phenomenon and contributes to service theory in terms of extending the consumer's role from production and creation to investment.

Kumar et al. (Ordanini et al., 2011) came up with an alternative means for voting thorough electronic means calling it the electronic voting. In their proposed system, they 
have made use of blockchain technology to make it more efficient and secure. Their main aim was to overcome the concern of a single point of failure that exists within the already existing client-server architecture.

Athreya et al. (2019) propose a unique way to adopt pets. Blockchain technology is used to store the details of the transaction. To get more details of the transaction, the hash value is used. It acts as a more convenient and easier platform for the adoption of pets. Thus, the distributed network acts as a more flexible and secures approach to the existing centralised network.

Baber (2019) came up with a new blockchain-based crowd-funding platform called WHIRL. The model is known as 'pay-it-forward'. Here, the members of a legit project will receive funds only when the help the members of the other projects to gain funds. Hartmann et al. (2019) had tried to bridge the gap between the conventional method of crowdfunding and the blackchain-based crowdfunding. The information provided paves a path for future researchers to work on the development process.

Zichichi et al. (2019) came up with a blockchain-based decentralised platform named 'LikeStarter'. Using this platform, a user would become popular on a social platform while raising funds. No central authority intervenes and the donors are continuously monitored which enables them to support. Hassija et al. (Zichichi et al., 2019) proposed a unique and secure crowdfunding platform using blockchain and Ethereum smart contracts. Algorithm used is the Hungarian algorithm. They have tried to eliminate the mutual negotiation between the developers and investors.

After a survey of these papers, the outcome observed is such that crowdfunding will be the most reliable method of raising money in the coming times and that blockchain will be the technology that will be used to make this platform efficient and secure. Crowdfunding will gain importance in all fields, especially in the financial sector. This method of collecting funds from the investors builds confidence within the community and helps the surfacing companies to showcase their ideas to the society boldly and network with the eminent.

\section{Existing methods}

Project characteristics such as the time duration, goal of funding, and the category of the project were found to be the tools of successful findings from the existing research. The existing models were not able to achieve high accuracy. The well known existing crowdfunding platforms such as Kickstarter and Indiegogo are known to be rewards-based type crowdfunding platforms. There are some popular donation-based crowdfunding platforms such as Crowdrise and GoFundMe. Donation-based crowdfunding can be performed on Indiegogo and even Kickstarter. However, this has to be done within the guidelines of their respective platforms. For example, an individual will not be able to donate funds that were raised to a charity or a specific cause.

There exist a large number of crowdfunding platforms throughout the world. Some of them include Crowdfunder, AngelList, CircleUp, Fundable, EarlyShares, Seedrs, and Crowdcube which are widely used in countries such as the USA, the UK and Europe. In other words, from the existing system, it is observed that the crowd is being involved to raise funds by forming a network of talented people who have great project ideas that would benefit society. We need a more secure and transparent system because the existing system has concerns such as security, interference of a third party, etc. 


\section{Decentralised application for crowdfunding using blockchain technology}

The hype of the terms cryptocurrency and crowdfunding is growing a lot on the internet these days. We can bridge the liabilities that are existing in both of these terms by using the technology of blockchain. A smart contract is written such that all money gets added to a pool of donations associated with the campaign. When the request meets the specified condition, then all the money will be transferred to the recipient after the approval of the bakers, i.e., more than $50 \%$ of the backers should approve only then it will be sanctioned.

Ethereum, a blockchain-based distributed platform along with its cryptocurrency called ether have been used for the testing of the proposed model. It provides a decentralised virtual machine called EVM that enables us to run the application on public nodes.

Figure 1 Architecture of the decentralised model

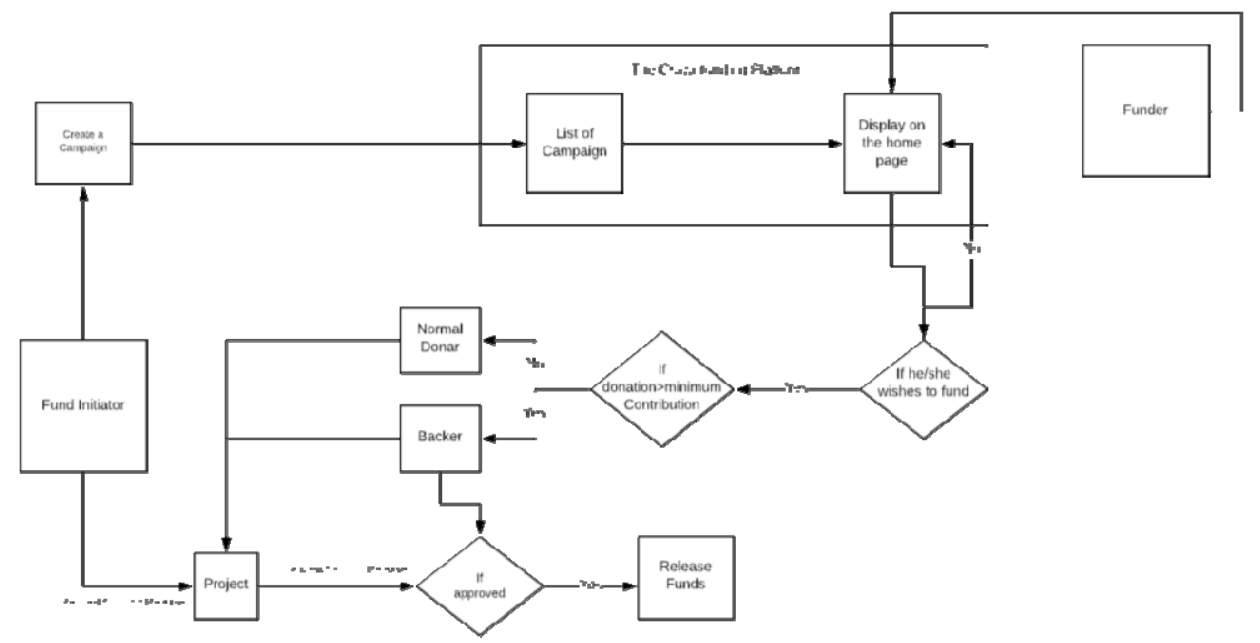

The following steps need to be fulfilled for the amount to be transferred to the client:

1 The fund initiator will create a campaign and list it on the platform.

2 All the projects will be displayed on the portal.

3 The funder will look through the portal to find the project he/she wants to fund.

4 Now, depending upon the amount that he/she is donating. The minimum contribution fixed by the fund initiator he/she will be considered a backer or a normal donor.

5 For the fund initiator to get the funds, he/she needs to request the backers for approval.

6 Once more than $50 \%$ of the backers approve the transaction, it will be directly given to the initiator without the involvement of any intermediate entity.

In distributed systems, the new transactions were added in such a way that non-value will be generated, and the hash value generated should be always less than targeted value and 
the process called mining. Miners compete against each other to figure out a hash value by solving a mathematical problem and receive a reward in terms of tokens or transaction fees. The common algorithm used is proof-of-work. This acts like a testament that the miner spent a substantial bulk of time and resources to figure out the solution to the problem. The miner needs to wait for a while before his transaction is confirmed and added to the block. Afterward, the reward is credited to the miner.

\subsection{Algorithm}

The Ethereum virtual machine runs the bytecode with 'inp' as input, and it can acquire data from the chain. The below algorithm shows a detailed example of a one-round consensus algorithm, which is used to measure the amount of work involved in calculating a problem. Here, the smaller min. work is, the problem is more difficult and the more work.

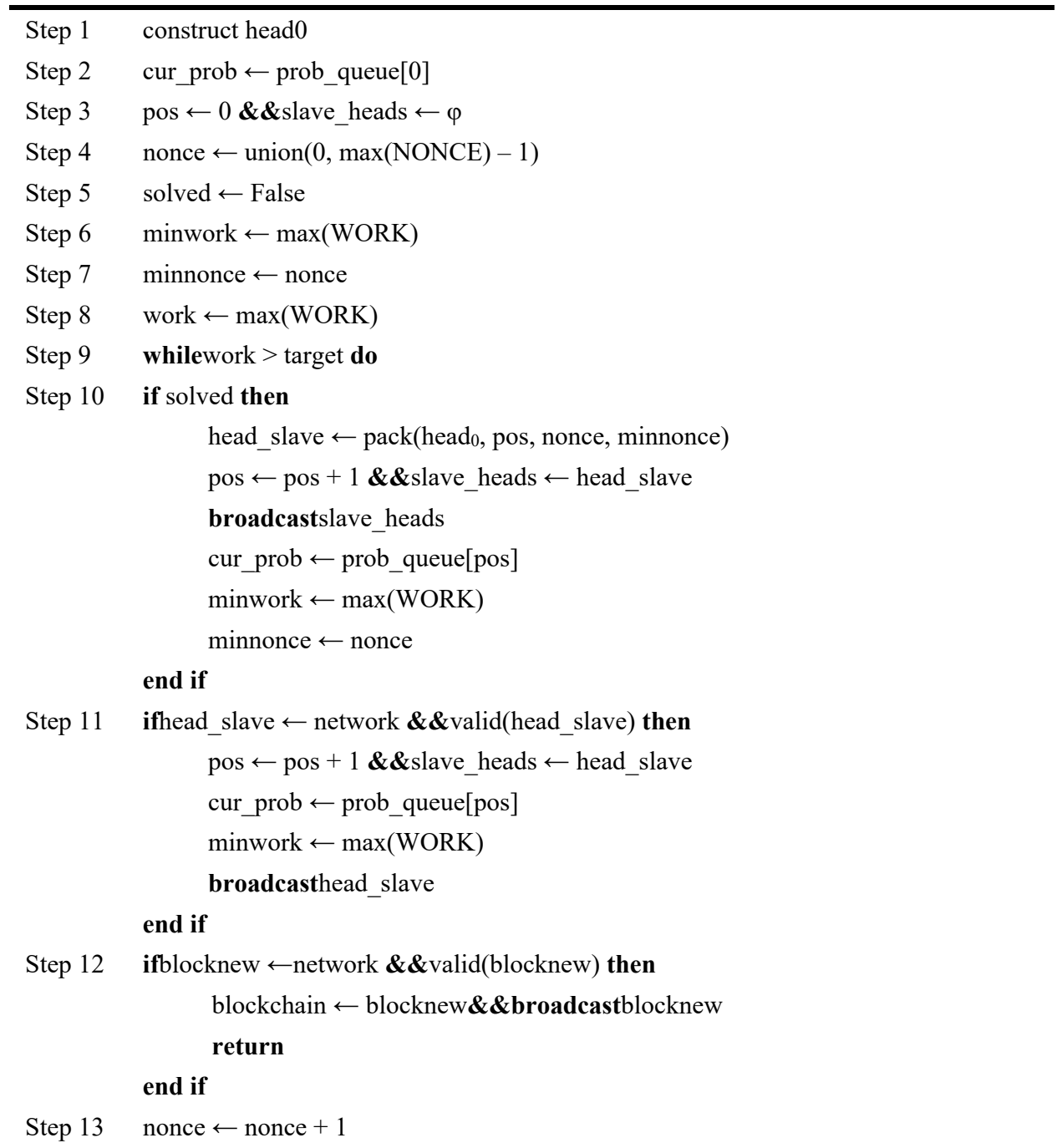


Step 14 work, solved $\leftarrow$ stackproof(head0, nonce, cur_prob)

Step 15 if work $<$ minworkthen

minwork $\leftarrow$ work $\& \&$ minnonce $\leftarrow$ nonce

end if

end while

Step 16 return

The blockchain is, in fact, represented as a singly linked list. Each block has a hash of the previous block - which can be thought of as a pointer to previous block. In the blockchain, each transaction in the block is stored in a Merkle tree. But the blockchain itself is not a tree. One of the major differences between a blockchain and a linked list is that you cannot remove or add a block in the middle of the list/chain. The way a blockchain is represented as a singly linked list. Each block has a hash of the previous block which can be thought of as a pointer to previous block. Some differences are that in a linked list, there are generally more operations for a linked list that are not available in a blockchain, most notably being able to remove a block and to add a block in the middle of the list/chain.

Let $\mathrm{U}$ here represent the initiator, $\mathrm{C}$ refers to the platform and $\mathrm{S}$ be all donors with $\mathrm{M}$ being the money to be invested on the project.

$$
\mathrm{M}=\mathrm{U} \cup\{\mathrm{C}\} \cup \mathrm{S}
$$

All the elements considered in S should have accounts in ETH.

All type of communications need to be carried out through the ETH account during the transfer of funds, this will end up recorded by ETH, represented by

$$
\mathrm{a} \underset{\mathrm{Memo}}{\stackrel{\mathrm{M}}{\longrightarrow} \mathrm{b}}
$$

where $\mathrm{M}$ is the object they want to send, and memo is the explanation donors want to explain. Applying function $\mathrm{f}$ to object $\mathrm{x}$ can be represented like $\mathrm{f}(\mathrm{x})$

$$
\mathrm{M}^{\prime}=\operatorname{Hash}(\mathrm{M}) \text {. }
$$

Encrypt or decrypt the message by function Enc(key, message) and Dec(key, message)

$$
\mathrm{M}^{\prime}=\operatorname{Enc}(\mathrm{pk}, \mathrm{m})
$$

where $\mathrm{M}^{\prime}$ is the encrypted value and the key is $\mathrm{pk}$.

The fitting and sampling procedure for the platform is carried out through the below-listed steps.

1 Fit a gmm to $\ln (\mathrm{GP})$

Determine $\mathrm{G}_{\mathrm{k}}$

$$
\begin{aligned}
& \text { Estimate for } \mathrm{i}=1 \text { to } \mathrm{G}, \sum \gamma_{\mathrm{i}}, \sum \alpha_{\mathrm{i}}^{2}, \sum \delta_{\mathrm{i}} \quad \text { \#Use EM algorithm } \\
& \mathrm{P}=\operatorname{gmm}\left(\mathrm{G}, \sum \gamma_{\mathrm{i}}, \sum \alpha_{\mathrm{i}}^{2}, \sum \delta_{\mathrm{i}}\right) \cdot \mathrm{fit}(\ln (\mathrm{GP}))
\end{aligned}
$$

2 Fit a gmm to $\ln (\mathrm{UG})$

Determine $\mathrm{G}_{\mathrm{k}}$ 


$$
\begin{aligned}
& \text { Estimate for } \mathrm{i}=1 \text { to } \mathrm{G}, \sum \gamma_{\mathrm{i}}, \sum \alpha_{\mathrm{i}}^{2}, \sum \delta_{\mathrm{i}} \quad \text { \#Use EM algorithm } \\
& \mathrm{P}=\operatorname{gmm}\left(\mathrm{G}, \sum \gamma_{\mathrm{i}}, \sum \alpha_{\mathrm{i}}^{2}, \sum \delta_{\mathrm{i}}\right) \cdot \mathrm{fit}(\ln (\mathrm{UG}))
\end{aligned}
$$

3 Fit a RFR to (UG, CTime)

Find out and optimisef, $r$.

$$
\beta=\operatorname{RFR}(f, r) . f i t(U G, C \text { Time })
$$

4 Test samples $\left(\mathrm{T}_{\mathrm{p}}, \mathrm{T}_{\mathrm{u}}, \mathrm{T}_{\mathrm{L}}, \mathrm{T}_{\mathrm{T}}\right)$

$$
\begin{aligned}
& \mathrm{T}_{\mathrm{p}}=\exp (\mathrm{P} \cdot \operatorname{sample}(\mathrm{s})) \\
& \mathrm{T}_{\mathrm{u}}=\exp (\mathrm{U} \cdot \operatorname{sample}(\mathrm{s})) \\
& \mathrm{T}_{\mathrm{L}}=\operatorname{Unif}\left(\mathrm{l}=\mathrm{T}_{\mathrm{u}}, \mathrm{h}=8 * 10^{6}, \text { limit }=\mathrm{s}\right)
\end{aligned}
$$

$\mathrm{T}_{\mathrm{T}}=\mathrm{T} \cdot \operatorname{predict}\left(\mathrm{T}_{\mathrm{u}}\right)$

\section{Results analysis}

Ethereum tokens were used to build this decentralised platform. When tokens are transferred from the metamask account to the project initiator account, a project is funded by the investor. All the transactions are thus stored on a block of a blockchain. The campaign or a project is said to be successful if it receives all targeted amount within the specified time. Else, the money is sent back to the investors through the backtracking method.

Figure 2 Create a campaign (see online version for colours)

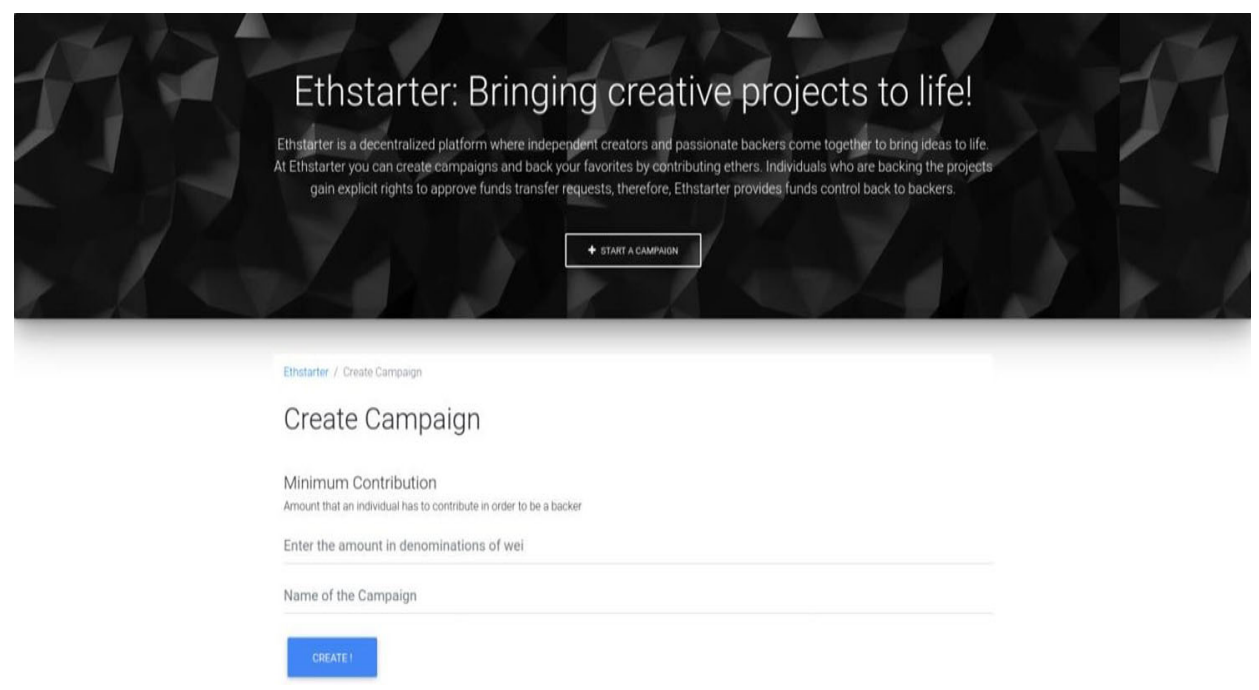

This is the page where the campaigns are created and a minimum amount is mentioned to meet the criteria of a funder. The investors can see the target amount and they will be aware of the backtracking option available where the money invested by them will be sent back if the target is not met. The campaign creators need to be highly innovative and 
visionary. This helps them to display their projects uniquely thus making the project look more unfeigned.

This page allows the funders to contribute their funds. The funders can invest as much as they want as there will not be any limit. Some projects might mention a certain minimum amount that needs to be invested. Otherwise, the investment can be as low as $\$ 10$. The investors can visit any project available, go through the details of the project, and invest in it only if they want to. The number of visits does not affect the contribution made by the investor.

Figure 3 Contribute (see online version for colours)

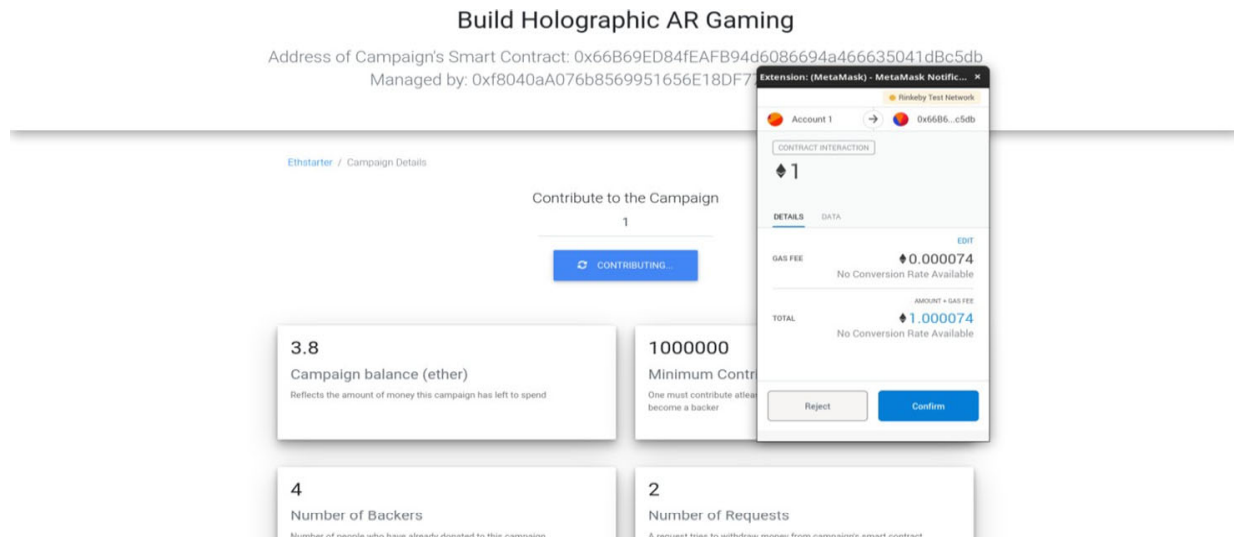

Figure 4 Campaign request (see online version for colours)

Build Holographic AR Gaming

Address of Campaign's Smart Contract: 0x66B69ED84fEAFB94d6086694a466635041 dBo5db Managed by: OXf8040aA0/6b8569957656E18DF//163A60586252

Campaign creator requests funds for a cause, to be released. After the campaign becomes successful, i.e., when the targeted amount is reached within the stipulated time, all the money needs to be released to the campaign creator by the crowdfunding platform. The campaign creators send a request to the platform to put up their campaign and provide all the necessary features such as transparency, efficiency, etc. If the campaign is successful, a small amount of fee is charged by the platform. 


\subsection{Graphical analysis}

Figure 5 shows a plot, i.e., bar graph which is a representation of time vs. contract functions. This helps us to demonstrate the latency of the called function.

Figure 5 Time vs. contract function (see online version for colours)

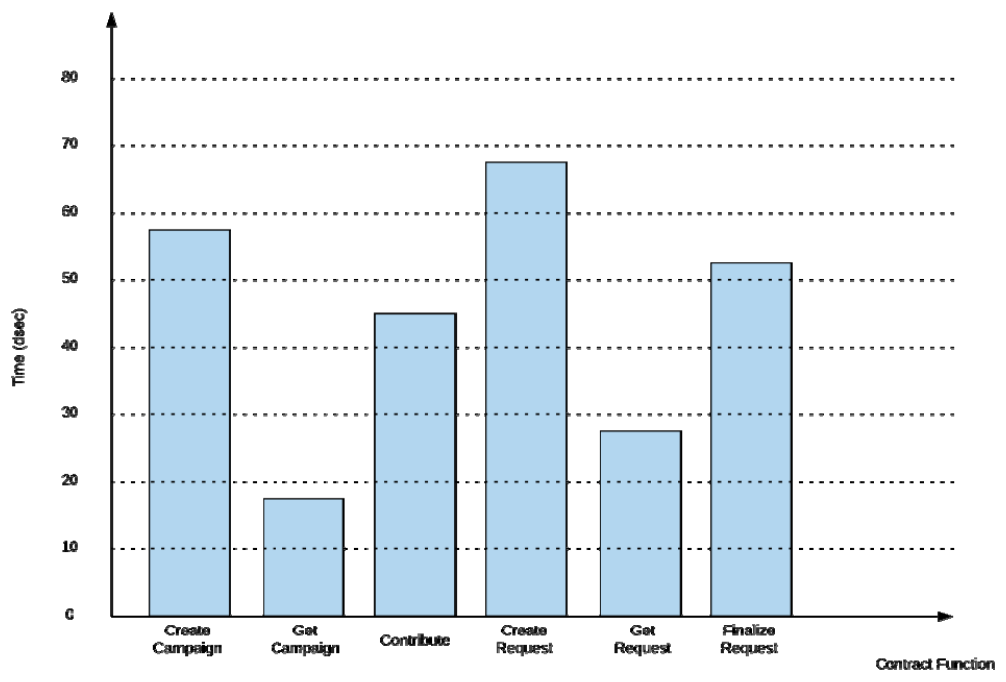

Figure 6 Gas vs. contract function (see online version for colours)

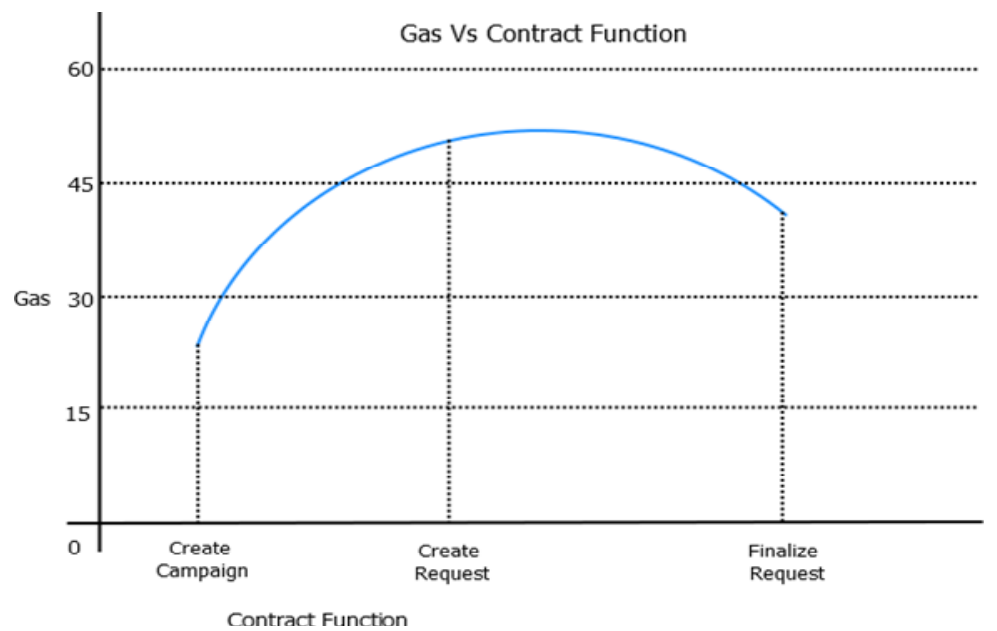

Figure 6 depicts the variation of gas cost (requirement) versus some of the key functions in the contract. The key functions are: creating a campaign, create request and finalising a request.

Figure 7 exhibits the overall performance of the contract according to the parameters on a test blockchain. The parameters considered are speed, integrity, upgradability, guards, modularity and cost efficiency. The overall security benchmark score is $76.15 \%$. 
Figure 7 Security benchmark score (see online version for colours)

Security Benchmark Score (76.15)

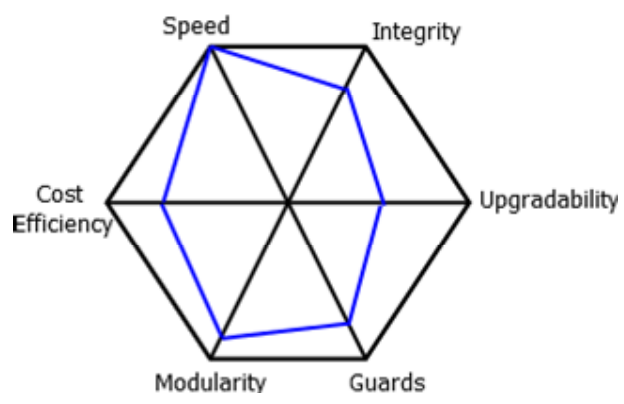

\section{Conclusions}

Crowdfunding is indubitably an evolving phenomenon. This platform acts as a great source for the organisations to get funds. It is credited with overcoming financial barriers. As the projects and ideas of a particular organisation are put up to the public, it grabs a huge amount of attention from its viewers which would help the company in the long run.

In this paper, we have proposed a decentralised platform for crowdfunding. Here, we eliminate the middle agents as well as the people who are accountable for flattening the system. The results obtained show the effective working of the system thus, making it highly secure, uncomplicated, and transparent when compared to the existing system which is a centralised and middle-man system. The project supports the initiators through a simple and secure GUI. This ensures that they launch their project without any complications and also help the investors to fund the projects easily. For integrity purposes, the transactions of ethers are stored in a blockchain. If the project initiated fails to raise funds within the stipulated time, it backtracks the transaction, thus forming a reliable system which the investors can depend upon. From the results thus obtained, it can be observed that the system is a highly precise and secure medium of raising funds.

\section{References}

Athreya, A.M., Kumar, A.A., Nagarajath, S.M. and Gururaj, H.L. (2019) 'Decentralized e-voting in crucial network using blockchain technology', Advances and Applications in Mathematical Sciences, July, Vol. 18, No. 9, pp.843-850.

Baber, H. (2019) 'Blockchain-based crowdfunding: a 'pay-it-forward' model of WHIRL', International Journal of Recent Technology and Engineering (IJRTE), September, Vol. 8, No. 3, pp.3225-3229, ISSN: 2277-3878.

Chen, Y. (2018) 'Blockchain tokens and the potential democratization of entrepreneurship and innovation', Business Horizons, Vol. 61, No. 4, pp.567-575.

Chiu, J. and Koeppl, T. (2017) The Economics of Cryptocurrencies [online] https://www.bis.org/events/eopix_1810/chiu_paper.pdf (accessed 2017).

Collins, R. (2016) 'Blockchain: a new architecture for digital content', EContent, Vol. 39, No. 8, pp.22-23. 
Gleasure, R. and Morgan, L. (2017) 'The pastoral crowd: exploring self-hosted crowdfunding using activity theory and social capital', Information Systems Journal, DOI: 101111/isj.12143.

Greenspan, G. (2015) MultiChain Private Blockchain, White Paper Founder and CEO, Coin Sciences Ltd. [online] https://www.multichain.com.

Gururaj, H.L., Manoj, A.A., Kumar, A.A., Nagarajath, S.M. and Ravi Kumar, V. (2020) 'Adoption of pets in distributed network using blockchain technology', Int. J. Blockchains and Cryptocurrencies, Vol. 1, No. 2, pp.107-120.

Hartmann, F., Grottolo, G., Wang, X. and Lunesu, M.I. (2019) 'Alternative fundraising: success factors for blockchain-based vs. conventional crowdfunding', in 2019 IEEE International Workshop on Blockchain Oriented Software Engineering (IWBOSE), IEEE, February, pp.38-43.

Knezevic, D. (2013) Impact of Blockchain Technology Platform in Changing the Financial Sector and Other Industries, DOI: 10.14254/1800-5845/2018.14-1.8.

Ordanini, A., Miceli, L., Pizzetti, M. and ParsuParasuraman, A. (2011) 'Crowd-funding: transforming customers into investors through innovative service platforms', Journal of Service Management, Vol. 22, No. 4, pp.443-470, DOI: 10.1108/09564231111155079.

Sahdev, N. (2017) Crowdfunding Meets Blockchain, DOI [online] http://dx.doi.org/10.2139/ssrn. 3047682 (accessed 15 July 2019).

Schär, F., Roth, J. and Schöpfer, A. (2019) 'The tokenization of assets: using blockchains for equity crowdfunding', SSRN Electronic Journal, September, Project: Decentralized Finance, DOI: $10.2139 /$ ssrn.3443382.

Schwartz, A.A. (2013) 'Crowdfunding securities', Notre Dame Law Review, Vol. 88, No. 1457, pp.457-490.

Tarun, S.S. (2015) 'Stakeholders in equity-based crowdfunding: respective risks over the equity crowdfunding lifecycle', Journal of Financial Innovation, Vol. 1, No. 2, pp.141-151, DOI: 10.15194/jofi \2015.vl.i2.34.

Tomczak, A. and Brem, A. (2013) 'A conceptualize investment model of crowdfunding', Venture Capital, Vol. 15, No. 4, pp.335-359, DOI: 10.1080/13691066.2013.847614.

Zichichi, M., Contu, M., Ferretti, S. and D'Angelo, G. (2019) 'LikeStarter: a smart-contract based social DAO for crowdfunding', in IEEE INFOCOM 2019, IEEE Conference on Computer Communications Workshops (INFOCOM WKSHPS), IEEE, April, pp.313-318. 